\title{
Enumeration, Antimicrobial Resistance and Typing of Salmonella enterica: Profile of Strains Carried in the Intestinal Contents of Pigs at Slaughter in Southern Brazil
}

\author{
Daniel Santos Paim' ', Caroline Pissetti', Tatiana Regina Vieira', Gabriela Orosco Werlang', \\ Eduardo de Freitas Costa', Jalusa Deon Kich² \& Marisa Cardoso'
}

\begin{abstract}
Background: Despite a strong association between Salmonella isolation and slaughter hygiene, as measured by the Enterobacteriaceae levels on pre-chill carcass surfaces, a high variation in this association was observed between sampling days within the same slaughterhouse. It was hypothesised that in a scenario of high exposure on the farm, batches with a high prevalence of carrier pigs shedding a high number of Salmonella may enhance the risk of contamination on some slaughter days. Thus, the aim of this study was to assess the profile of Salmonella carried in the intestinal contents of slaughter pigs. Materials, Methods \& Results: Ten pig batches slaughtered in a slaughterhouse were investigated for the presence of Salmonella. From each pig, the following samples were taken: $i$. blood collected at bleeding; $i$. sponges rubbed on the carcass surface after bleeding and before chilling; iii. fragment of the ileocecal region of the intestine. Serum samples were subjected to a ELISA-Typhimurium test. Sponges were investigated for the presence of Salmonella and total aerobic mesophilic (TAM) and Enterobacteriaceae (EC) bacterial counts. Salmonella was enumerated in the intestinal contents. Selected Salmonella strains were subjected to an antimicrobial resistance disk diffusion test, macro-restriction with Xba-I (PFGE) and whole genome sequencing (WGS). From the 50 sampled pigs, 96\% were positive in the ELISA-Typhimurium test and $64 \%$ were Salmonella-positive in the intestinal contents. The amount of Salmonella in the intestinal content samples was highly variable, and the mean log of fitted distributions of Salmonella in the batch ranged from -2.97 to $2.25 \mathrm{cfu}^{-\mathrm{g}^{-1}}$. The slaughter process achieved a logarithmic reduction, ranging from 0.64 to $2.35 \log \mathrm{cfu}^{-\mathrm{cm}^{-2}}$ for TAM and from 0.55 to $2.57 \mathrm{log} \mathrm{cfu}^{-\mathrm{cm}^{-2}}$ for EC. Salmonella was isolated from $16 \%$ of the carcasses after bleeding; this frequency decreased to $8 \%$ at the pre-chill step. All positive pre-chill carcasses originated from pigs carrying Salmonella in the intestinal content and from batches with a high number of carrier pigs. Salmonella Typhimurium and its monophasic variant were the most frequent in the intestinal contents and carcasses. Resistance was detected against ampicillin (42.5\%), tetracycline (42.5\%), sulfonamide (40\%), gentamicin (25\%) and ciprofloxacin (12.5\%). Regarding colistin, $85 \%$ of the tested strains were classified as non-susceptible. The monophasic variant $S$. Typhimurium strains subjected to PFGE and WGS presented different profiles; several antimicrobial resistance genes were identified and all belonged to ST-19.

Discussion: In this study, almost all sampled pigs entering the slaughter line had been exposed to Salmonella on the farm and a high number were carrying Salmonella in their guts. While the three batches with Salmonella-positive carcasses at the pre-chill step presented TAM media that was not significantly different from the other batches, there was a higher number of positive pigs carrying Salmonella in their intestinal contents. Moreover, the batch with the highest number of positive carcasses also presented the highest Salmonella mean count in their intestinal contents. The profile of Salmonella carried in the intestinal content of slaughter pigs proved to be highly variable in terms of the frequency, number of bacteria, serovars, antimicrobial resistance, and genotypes. Results indicate that the day-to-day variability in the prevalence and number of Salmonella in the intestinal contents of slaughter batches is likely to influence the frequency of contaminated pre-chill carcasses. Salmonella Typhimurium isolated from the intestinal contents of slaughter pigs may belong to genotypes involved in human disease and may carry several antimicrobial resistance genes. These aspects should be taken into account when planning Salmonella control in swine.
\end{abstract}

Keywords: Salmonella Typhimurium monophasic variant, faecal excretion, enterobacteria, total aerobic mesophilic bacteria, $m c r-1$ gene, whole genome sequencing.

DOI: $10.22456 / 1679-9216.89668$

Accepted: 30 January 2019

Published: 19 February 2019 ${ }^{1}$ Departamento de Medicina Veterinária Preventiva, Faculdade de Veterinária, Universidade Federal do Rio Grande do Sul (UFRGS). Porto Alegre, RS,
Brazil. ${ }^{2}$ Embrapa Swine and Poultry, Concórdia, SC, Brazil. CORRESPONDENCE: M. Cardoso [mcardoso@ufrgs.br - Tel.: +55 (51) 3308-6123]. Av. Bento Gonçalves n. 9090. Bairro Agronomia. CEP 91540-000 Porto Alegre, RS, Brazil. 


\section{INTRODUCTION}

Salmonella control programmes targeting the poultry and swine production chains have been associated with a decreased prevalence of salmonellosis in humans [17]. In the European Union, the Salmonella control programme for swine has been based on the "from farm to fork" strategy, which includes on-farm interventions, the monitoring of Salmonella frequency in carcasses, and slaughter hygiene [1]. Salmonella control in the United States, in turn, is based mainly on improvements in slaughter hygiene; this approach has proved to be reliable and cost-effective [16]. In Brazil, a monitoring programme for slaughter hygiene and Salmonella frequency in pig carcasses has recently been published [8].

Previous studies conducted in southern Brazil demonstrated high Salmonella seroprevalence in slaughter pigs and a variable prevalence (from $8.7 \%$ to $24 \%$ ) of Salmonella on pre-chill carcasses [15,25,42]. In Brazilian slaughterhouses, despite a strong association between Salmonella isolation and slaughter hygiene measured by the Enterobacteriaceae levels on pre-chill carcasses surfaces, a high variation in this association was observed between sampling days in any given slaughterhouse. It was hypothesised that in a scenario of high exposure on the farm, batches with a high prevalence of carrier pigs shedding a high number of Salmonella may enhance the hazard of contamination on some slaughter days. In this scenario, even a hygienic process would fail to avoid the presence of Salmonella on some carcasses [15]. Thus, the aim of this study was to assess the profile of Salmonella carried in the intestinal contents of slaughter pigs and the contamination of pre-chill carcasses.

\section{MATERIALS AND METHODS}

\section{Study design and sampling}

Ten pig batches slaughtered in a slaughterhouse located in Rio Grande do Sul were investigated for the presence of Salmonella. Pig batches were kept at the lairage for up to 8 hours; live animals were washed before entering the stunning and exsanguination area. The remaining slaughter steps were conducted as described by Silva et al. [43]. In order to minimise the effect of previous slaughter batches on the Salmonella environmental contamination, the first slaughtered batch for 10 consecutive days was sampled. From each batch, the fifth pig entering the slaughter line was included in the study and four other pigs, over an interval of $15 \mathrm{~min}$, were also sampled. Pigs were marked in the left ear in order to be followed during the dressing process. From each pig, the following samples were taken: $i$. blood collected at bleeding; $i$. sponges ${ }^{1}$ rubbed on the carcass surface $\left(400 \mathrm{~cm}^{2}\right)$ after bleeding and before chilling; iii. fragment of the ileocecal region of the intestine.

\section{ELISA-Typhimurium}

Serum samples were tested by the ELISA-Typhimurium test [27], with a cut-off value of $20 \%$ [26].

Total aerobic mesophilic (TAM) and Salmonella isolation and enumeration by the most probable number (MPN)

Sponges taken from the carcasses after bleeding and before chilling were individually suspended in $30 \mathrm{~mL}$ of $0.1 \%$ buffered peptone water and $5 \mathrm{~mL}$ of suspension was used for total aerobic mesophilic (TAM) and Enterobacteriaceae (EC) enumeration [43]. The TAM and EC results were calculated as CFU.cm ${ }^{-2}$ and transformed into $\log _{10}$ for analysis. Means of $\log _{10}$ CFU.cm ${ }^{-2}$ TAM and EC were compared by the Tukey test $(P=0.05)$ using SPSS software. The remaining suspension volume from each sponge was added to $225 \mathrm{~mL}$ of $1 \%$ buffered peptone water and subjected to Salmonella detection [24].

From the ileocecal region of the intestine, $25 \mathrm{~g}$ of intestinal contents were suspended in 225 $\mathrm{mL}$ of $1 \%$ buffered peptone water and subjected to Salmonella detection [24]. Intestinal contents were also subjected to Salmonella enumeration by the miniaturised most probable number (MPN) protocol described by Tavares [44], with modifications [34]. The MPN was calculated by the MPN Calculator (http://www.i2workout.com/mcuriale/mpn/index. html). Distrubutions of the concentrations of Salmonella sp. $\left(\log\right.$ cfu. $\left.\mathrm{g}^{-1}\right)$ in the sampled faeces were fitted using the maximum likelihood method [11] with the fitdistrplus package [18] of R software [39]. The method is suitable for estimating distributions with censored data, as is the case for MPN results and microbiological testing. In this model, the results of the screening test performed on the $25 \mathrm{~g}$ sample are considered together with the results of the MPN. In 
this approach, a negative result in the screening is considered left censored (i.e. less than one bacterium in $25 \mathrm{~g}$ or less than $\left.0.04 \mathrm{cfu} \cdot \mathrm{g}^{-1}\right)$. Positive samples in the screening that were negative in the MPN are considered interval censorsed, while positive samples in the screening and in a finite number of MPN tubes are considered uncensored data. Finally, samples positive in the screening and presenting all positive MPN tubes are considered right censored data. Salmonella isolates were serotyped at the Fundação Instituto Oswaldo Cruz.

\section{Antimicrobial resistance}

All Salmonella strains were subjected to an antimicrobial susceptibility test against 12 antimicrobials by the disk-diffusion method, performed and interpreted by the Clinical and Laboratory Standards Institute, documents VET08 and M100 $[13,14]$. The following antimicrobials disks ${ }^{2}$ were tested: ampicillin $(10 \mu \mathrm{g})$, azithromycin $(15 \mu \mathrm{g})$, cefotaxime $(30 \mu \mathrm{g})$, cefoxitin $(30 \mu \mathrm{g})$, ceftazidime $(30 \mu \mathrm{g})$, ceftiofur $(30 \mu \mathrm{g})$, ceftriaxone $(30 \mu \mathrm{g})$, ciprofloxacin $(5 \mu \mathrm{g})$, gentamicin $(10 \mu \mathrm{g})$, meropenem $(10 \mu \mathrm{g})$, sulfonamide $(300 \mu \mathrm{g})$ and tetracycline $(30$ $\mu \mathrm{g})$. Furthermore, the minimum inhibitory concentration (MIC) of colistin was also determined [21]. Escherichia coli ATCC® 25922 was used for quality control purposes. The strains were also screened for the presence of the $m c r-1$ gene by PCR with primers CLR5-F (5'-CGG TCA GTC CGT TTG TTC-3') and CLR5-R (5'-CTT GGT CGG TCT GTA GGG-3') [32].

\section{Pulsed-field gel eletrophoresis (PFGE)}

According to the serotyping profile, Salmonella strains were chosen to be subjected to pulsedfield gel eletrophoresis (PFGE) analysis, following the procedures of Pulse-Net (https://www.cdc.gov/ pulsenet/pathogens/pfge.html). Isolates were digested with $\mathrm{XbaI}^{3}$ and eletrophoresis was performed in a $1 \%$ agarose gel using 0.5X Tris-borate-EDTA buffer on a CHEF DR-II system ${ }^{4}$; this was done at $6 \mathrm{~V} / \mathrm{cm}$ for $20 \mathrm{~h}$ at $14{ }^{\circ} \mathrm{C}$ with an initial switch time of $2.2 \mathrm{~s}$ and a final switch time of $63.8 \mathrm{~s}$. After PFGE, the gel was stained with ethidium bromide $(2 \mu \mathrm{g} / \mathrm{mL})$, photographed under UV transilumination and the image digitalisation was processed by the L-Pix Touch System 5 . PFGE-banding patterns were compared using the Gel-Compar II software package $^{6}$. Similarities between profiles were cal- culated using the Dice coefficient, with $1.7 \%$ tolerance [12]. The patterns were clustered using the unweighted pair group method with arithmetic averages (UPGMA) and dendrograms were constructed.

Whole genome sequencing and multilocus sequence typing (MLST)

Chromosomal DNA of the subset of Salmonella strains was sequenced by MicrobesNG ${ }^{7}$. The genomic DNA was extracted using a PureLink Genomic DNA ${ }^{8}$ kit, purified, resuspendend in EB buffer and quantified by QuantusTM Fluorometer dsDNA ${ }^{3}$. Genomic DNA libraries were prepared using a Nextera XT Library Prep Kit ${ }^{9}$. DNA quantification and library preparation were conducted on a Hamilton Microlab STAR Automated Liquid Handling System. Pooled libraries were quantified using the Kapa Biosystems Library Quantification Kit for Illumina on a Roche LightCycler 96 qPCR machine. Libraries were sequenced on the Illumina HiSeq ${ }^{9}$ using a 250 bp paired end protocol. Reads were adapter trimmed using Trimmomatic 0.30 with a sliding window quality cutoff of Q15 [5]. De novo assembly was performed on samples using SPAdes version 3.7 [3] and contigs were annotated using Prokka 1.11 [41]. The web-servers MLST version 2.0.1 [28] and ResFinder version 3.1 [47], available at the Center for Genomic Epidemiology (CGE) (www. genomicepidemiology.org), were used to identify the multilocus sequence type (ST), chromosomal mutations and acquired antimicrobial resistance gene in genome with a selected threshold for $98 \%$ sameness. The identification and results of the ResFinder were compared with phenotypic antimicrobial susceptibility testing results. Serotyping was confirmed with SeqSero version 1.2, hosted by CGE [49].

\section{RESULTS}

From the 50 sampled pigs, $48(96 \%)$ were positive in the ELISA-Typhimurium test, and $64 \%$ $(32 / 50)$ of them were Salmonella positive in their intestinal contents. Pigs positive for Salmonella isolation were found in all 10 sampled batches, and the number of pigs carrying Salmonella per batch varied from one to five. The amount of Salmonella in the intestinal content samples of individual carrier pigs was highly variable, and the mean log of fitted distributions of Salmonella in the batch ranged from -2.97 cfu.g $^{-1}$ (SD 6.8 cfu.g ${ }^{-1}$ ) to 2.25 cfu.g $^{-1}$ (SD 0.47 cfu. $\left.^{-1}\right)$, as depicted in Figure 1 . 


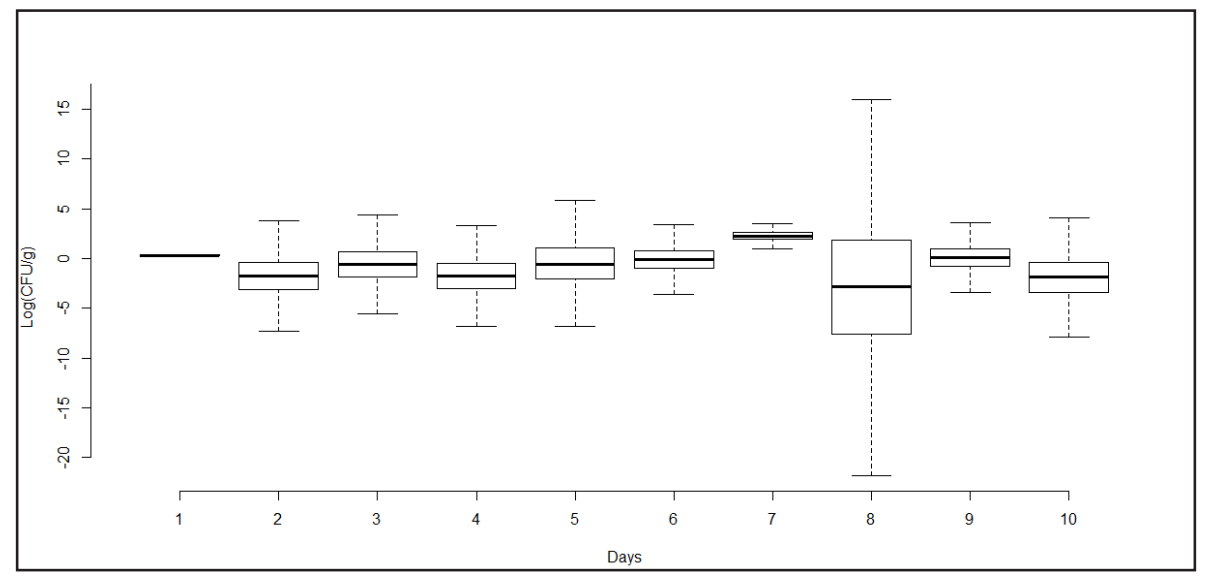

Figure 1. Fitted distribution of Salmonella sp. (log cfu.g-1) in the faeces of pig batches slaughtered over 10 different days.

The mean values of TAM and EC bacteria on the carcasses sampled after bleeding over 10 slaughter days varied from 2.64 to $3.58 \mathrm{log}$ cfu.cm $\mathrm{cm}^{-2}$ and 0.27 to $2.64 \mathrm{log}$ cfu.cm ${ }^{-2}$, respectively (Tables 1 and 2). At the pre-chill step, the day-to-day mean of TAM bacteria ranged from 1.43 to $2.48 \mathrm{log}$ cfu.cm ${ }^{2}$, and the EC mean bacteria count ranged from -0.8 to $0.46 \log$ cfu. $\mathrm{cm}^{2}$. The logarithmic reduction achieved by the slaughter process varied from 0.64 to $2.35 \mathrm{log}$ cfu.cm ${ }^{-2}$ for TAM bacteria and from 0.55 to $2.57 \log$ cfu.cm ${ }^{-2}$ for EC. Salmonella was isolated from $16 \%$ (8/50) of the carcasses after bleeding; this frequency decreased to $8 \%(4 / 50)$ at the pre-chill step. Taking into account the four Salmonella-positive carcasses at the pre-chill step, two were originated from a common slaughter batch (\#7), and the remaining two were from two different slaughter batches (\#3 and \#5). All positive pre-chill carcasses originated from pigs carrying Salmonella in their intestinal contents and from batches with a high number of carrier pigs ( $4 / 5$ in batch \#3 and 5/5 in batches \#5 and \#7).

Salmonella Typhimurium monophasic variant (S. 1,4,[5],12:-:1,2) was the most frequent serovar identified in the positive intestinal content samples (18/32; $56.25 \%$ ). On the positive carcasses, $S$. Typhimurium predominated (5/12), followed by $S$. Derby (3/12) (Table 3).

Table 1. Mean logarithmic counts (log.cm-2) of total aerobic mesophilic (TAM) bacteria on carcasses, after bleeding and before chilling, of pigs slaughtered in an abattoir in Rio Grande do Sul, Brazil.

\begin{tabular}{cccc}
\hline & \multicolumn{2}{c}{ Slaughter step } & \multirow{2}{*}{ Mean logarithmic reduction } \\
\cline { 2 - 3 } Slaughter batch & After bleeding & Before chilling & \\
\cline { 2 - 3 } & $\begin{array}{c}\text { Mean log TAM.cm }{ }^{-2} \\
(\text { Min. - Max.) }\end{array}$ & $\begin{array}{c}\text { Mean log TAM. cm }{ }^{-2} \\
(\text { Min. - Max.) }\end{array}$ & 0.93 \\
\hline 01 & $2.95(2.67-3.36)^{\mathrm{cd}}$ & $2.02(1.36-2.64)^{\mathrm{ab}}$ & 1.51 \\
02 & $3.27(2.90-3.45)^{\mathrm{bcd}}$ & $1.76(1.26-1.97)^{\mathrm{ab}}$ & 1.77 \\
03 & $4.25(3.80-4.89)^{\mathrm{a}}$ & $2.48(1.85-3.20)^{\mathrm{a}}$ & 1.65 \\
04 & $3.09(2.87-3.57)^{\mathrm{bcd}}$ & $1.44(0.97-1.65)^{\mathrm{b}}$ & 2.35 \\
05 & $3.78(3.48-3.92)^{\mathrm{ab}}$ & $1.43(1.08-2.03)^{\mathrm{b}}$ & 1.17 \\
06 & $3.03(2.72-4.03)^{\mathrm{cd}}$ & $1.86(1.06-2.80)^{\mathrm{ab}}$ & 1.67 \\
07 & $3.52(2.78-3.92)^{\mathrm{abc}}$ & $1.85(1.34-2.51)^{\mathrm{ab}}$ & 0.64 \\
08 & $2.64(2.00-3.27)^{\mathrm{d}}$ & $2.00(1.72-2.37)^{\mathrm{ab}}$ & 1.56 \\
09 & $3.35(3.02-3.69)^{\mathrm{bcd}}$ & $1.79(1.43-2.14)^{\mathrm{ab}}$ & 1.28 \\
10 & $2.91(2.79-3.13)^{\mathrm{cd}}$ & $1.63(1.23-2.01)^{\mathrm{ab}}$ & \\
\hline
\end{tabular}

Different superscript letters in a row indicate significantly different means, according to a Tukey test $(P<0.05)$. 
Table 2. Mean logarithmic counts $\left(\log . \mathrm{cm}^{-2}\right)$ of Enterobacteriaceae (EC) bacteria on carcasses, after bleeding and before chilling, of pigs slaughtered in an abattoir in Rio Grande do Sul, Brazil.

\begin{tabular}{|c|c|c|c|}
\hline \multirow{3}{*}{ Slaughter batch } & \multicolumn{2}{|c|}{ Slaughter step } & \multirow{3}{*}{ Mean logarithmic reduction } \\
\hline & After bleeding & Before chilling & \\
\hline & $\begin{array}{l}\text { Mean log EC.cm } \\
\text { (Min. - Max.) }\end{array}$ & $\begin{array}{l}\text { Mean log EC.cm-2 } \\
\text { (Min. - Max.) }\end{array}$ & \\
\hline 01 & $0.80\left(\mathrm{ND}^{*}-1.00\right)^{*}$ & $-0.71(\mathrm{ND}--0.30)$ & 1.51 \\
\hline 02 & $1.33(0.57-2.41)$ & $-0.50(-1.00-0.00)$ & 1.83 \\
\hline 03 & $2.64(2.00-3.04)$ & $0.23(-0.15-0.77)$ & 2.41 \\
\hline 04 & $0.93(0.38-1.63)$ & $-0.80(\mathrm{ND}--0.70)$ & 1.73 \\
\hline 05 & $2.16(1.64-3.05)$ & $-0.41(-1.00-0.18)$ & 2.57 \\
\hline 06 & $1.45(0.32-3.05)$ & $0.46(\mathrm{ND}-1.03)$ & 0.99 \\
\hline 07 & $1.18(1.02-1.42)$ & $-0.42(-0.70-0.20)$ & 1.60 \\
\hline 08 & $0.27(-1.00-1.12)$ & $-0.28(-0.70--0.05)$ & 0.55 \\
\hline 09 & $1.12(0.11-1.98)$ & $-0.34(\mathrm{ND}--0.22)$ & 1.46 \\
\hline 10 & $0.45(0.00-0.96)$ & $-0.22(-1.00-0.32)$ & 0.68 \\
\hline
\end{tabular}

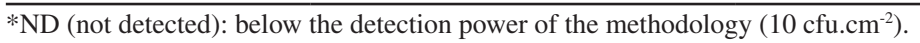

Table 3. Serovars of Salmonella enterica isolated from intestinal contents and pig carcasses sampled after bleeding and before chilling in a slaughterhouse in Rio Grande do Sul, Brazil.

\begin{tabular}{cccc}
\hline \multirow{2}{*}{ Slaughter batch } & Intestinal contents (n. positive samples) & \multicolumn{2}{c}{ Carcasses (n. positive samples) } \\
\cline { 3 - 4 } & Typhimurium monophasic variant (2) & After bleeding & Before chilling \\
\hline 01 & Mbandaka (1) & - & - \\
02 & Typhimurium monophasic variant (4) & - & Derby (1) \\
03 & Infantis (1) & - & O:4,5 (1) \\
04 & Typhimurium monophasic variant (2); Derby (1); & Typhimurium (1); Derby (1); & O:4,5 (1) \\
05 & Typhimurium monophasic variant (4) & Typhimurium (1) & - \\
06 & Typhimurium monophasic variant (3); & Typhimurium (2); Panama (1) & Typhimurium \\
& Typhimurium (1); Panama (1) Infantis (1) & - \\
07 & Typhimurium monophasic variant (2) & - & - \\
08 & Panama (2); Infantis (1) & - & - \\
09 & Typhimurium monophasic variant (1); Infantis (1) & - & - \\
\hline
\end{tabular}

All the tested Salmonella strains isolated from intestinal contents $(n=28)$ and carcasses $(n=12)$ were fully susceptible to azithromycin, cephalosporins (cefotaxime, cefoxitin, ceftazidime, ceftiofur, and ceftriaxone) and meropenem. Resistance was detected against ampicillin $(\mathrm{n}=17 ; 42.5 \%)$, tetracycline $(\mathrm{n}=17 ; 42.5 \%)$, sulfonamide $(\mathrm{n}=16 ; 40 \%)$, gentamicin $(\mathrm{n}=10 ; 25 \%)$, and ciprofloxacin $(n=5 ; 12.5 \%)$. A total of six strains $(15 \%)$ were susceptible to all tested antimicrobials and 17 (42.5\%) were multi-drug resistant (MDR) strains (resistant to $\geq 3$ antimicrobial classes). Regarding colistin, 85\% (34/40) of the tested strains were classified as non-susceptible (MIC $\left.>2 \mu \mathrm{g} \cdot \mathrm{mL}^{-1}\right)$. In four of the non-susceptible strains (4/34;
$11.8 \%$ ), the gene $m c r-1$ was detected; all positive strains were $S$. Typhimurium monophasic variant and presented a MDR profile. In all $\mathrm{mcr}$-1-positive strains, the MIC value for colistin was $8 \mu \mathrm{g} . \mathrm{mL}^{-1}$; however, in one strain presenting this MIC, the $m c r-1$ gene was not detected.

The seven monophasic variant $S$. Typhimurium strains subjected to PFGE presented five different profiles; the pulsotype SM-1 encompassed three strains isolated from a common slaughter batch, presenting a common antimicrobial resistance profile and carrying the $m c r-1$ gene. The remaining PFGE pulsotypes included single strains with variable resistance profiles and originated from different pig batches (Figure 2). 


\begin{tabular}{|l|l|lllll}
\hline & \\
\end{tabular}

Figure 2. (A) Macro restriction profiles, antimicrobial resistance, amplification of $m c r-1$ gene and colistin minimum inhibitory concentration (MIC) of the Salmonella Typhimurium monophasic variant isolated from the intestinal contents of slaughtered pigs. (B) Multilocus sequence type (MLST) and resistance gene profile of strains subjected to whole genome sequencing (marked with an asterisk). Amp = ampicillin; Gen = gentamicin; Sul $=$ sulfonamide; Tet = tetracycline; NA = non-applicable.

In order to further characterise the monophasic variant of Salmonella non-susceptible to colistin, five strains, which are indicated with an asterisk in Figure 2, were subjected to whole genome sequencing (WGS). The two strains (\#74 and \#76) belonging to the same pulsotype proved to carry the same genes conferring resistance to aminoglycosides, ampicillin, sulfonamide and tetracycline. Both strains presented the same mutation in the genes gyrA and carried qnrB; however, in the disk diffusion test, they were classified as intermediately resistant to ciprofloxacin. Colistin resistance was related to the presence of $m c r-1$. Strain \#78, although isolated from this same slaughter-batch and presenting a MIC of $8 \mu \mathrm{g} \cdot \mathrm{mL}^{-1}$, did not carry any $m c r$ gene and the resistance gene profile was distinct. In this strain, additional aminoglycoside resistance genes ( $a a d$ and $a p h$ ) were present, as well as genes codifying resistance against trimethoprim (drfA12) and the amphenicol class (cmlAl and $f l o R)$. Strain \#41, which was isolated on a different slaughter day but had the $m c r-1$ gene, as detected by PCR, also presented the $m c r l .1$ variant. Moreover, this strain presented the highest number of resistance genes (13 genes as well as the mutation on gyrA), and carried a large diversity of aph genes conferring resistance to aminoglycosides. Strain \#97 grouped close to the latter in PFGE and was isolated on a different slaughter day; it presented a colistin MIC of $4 \mu \mathrm{g} . \mathrm{mL}^{-1}$ and was negative in the $m c r-1$ amplification. WGS confirmed that no $\mathrm{mcr}$ gene type was present in this strain, while genes codifying resistance to ampi- cillin, aminoglycosides, amphenicol and tetracycline were detected. In spite of the diversity in the resistance genes, all strains were classified in a common sequence type (ST), namely ST-19.

\section{DISCUSSION}

In this study, almost all sampled pigs entering the slaughter line were seropositive in the ELISA test, demonstrating that they had been exposed to Salmonella on the farm. Moreover, a high number of the sampled pigs were carrying Salmonella in their guts. Serology gives historical information [26,27], thus a positive result in the ELISA-Typhimurium test cannot be interpreted as an active infection at slaughter, but indicates that the pig was infected on the farm. However, seropositive pig batches have higher chances of including carrier individuals, which may be excreting Salmonella at slaughter $[4,7,40]$. In fact, in the 10 sampled slaughter batches, at least one pig was carrying Salmonella in the gut, demonstrating a continuous source of contamination to the slaughter process represented by seropositive pig batches. In Brazil, a high prevalence of Salmonella carrier pigs at slaughter has already been reported [25,42], which may turn out to be a bottle neck in the control of Salmonella in pork.

The high burden of Salmonella-carrier pigs to the slaughter process makes hygiene of utmost importance, and avoiding contact of the carcass with intestinal contents and the environment contaminated 
with faeces is key for maintaining the carcass status. The hygienic measures, in turn, should begin before slaughter; it has been demonstrated that lower total bacteria counts were found on the body surface of pigs that were washed before slaughter [36]. This suggests that washing may contribute not only to visibly clean animals [7], but also to lower bacterial counts on carcasses at the beginning of the process. In this study, TAM mean bacteria counts below $4 \log$ cfu. $\mathrm{cm}^{-2}$ were detected in all batches, much lower than that reported (6 log cfu.cm ${ }^{-2}$ ) by Pearce et al. [36] when washing was not performed.

In the slaughter process, some steps, such as singeing, can decrease superficial microbial contamination, while others represent a hazard of adding bacteria to the surface of the carcass $[7,10,36]$. The monitoring of hygiene indicators, such as TAM and $\mathrm{EC}$, plays a role in reflecting the contamination/decontamination profile throughout processing. In fact, these results demonstrate that the process in place at the studied slaughterhouse was able to achieve logarithmic reductions of up to $2.5 \log$ for TAM and EC bacteria counts. At the end of the slaughter line, mean counts of TAM and EC were below $3 \log \mathrm{cfu} . \mathrm{cm}^{-2}$ and $1 \log$ cfu.cm ${ }^{-2}$, respectively. These mean counts are in accordance with those reported in studies conducted in slaughterhouses with hygienic process measures $[19,36,50]$, and they are in compliance with the limits established in Brazil [8]. Therefore, on all slaughter days, the process proved to be in accordance with good hygienic standards.

Regarding Salmonella, slaughter processing was able to halve the number of positive carcasses detected after bleeding, despite $64 \%$ of the sampled pigs carrying Salmonella in their guts. A frequency of $8 \%$ Salmonella-positive carcasses found at the pre-chill step was reported in previous studies conducted in Brazil $[15,25]$ and is in accordance with the prevalence estimated by a national exploratory study conducted by Brasileiro et al. [9]. However, the day-to-day variation was similar to previously reported variations [15]. Salmonella-carrier pigs are recognised as the main source of contamination at slaughter, and the number of pigs excreting Salmonella is an important factor for carcass contamination $[4,10,17]$. Still, data about the number of Salmonella carried in the intestinal contents of pigs at slaughter and its relationship with the carcass status are scarce. In a study conducted in the Netherlands, the mean number of Salmonella carried in pig rectums at slaughter varied from -3.32 to $2.71 \log$ MPN.g ${ }^{-1}$ over 11 sampling days, demonstrating high variability in the number of Salmonella excreted by pigs [45]. In the aforementioned study, however, the influence of this variation on the frequency of Salmonella in carcasses was not investigated. While in our study the three batches with Salmonella-positive carcasses at the pre-chill step presented TAM media that was not significantly different from the other batches, there was a higher number of positive pigs carrying Salmonella in their intestinal contents. Moreover, the batch with the highest number of positive carcasses also presented the highest Salmonella mean count $\left(2.25 \mathrm{log} \mathrm{cfu}^{-1} \mathrm{~g}^{-1}\right)$ in the intestinal contents of the pigs. Although the Salmonella strains detected in the intestinal contents and positive carcasses belonged to different variants or serovars, the burden of the number of Salmonella in the gut to the slaughter process can be inferred. Moreover, it was demonstrated that $S$. Typhimurium and its monophasic variant predominated in both carcass and intestinal content samples. Over the years, Salmonella Typhimurium has been the most prevalent serovar reported in swine in Brazil [25,42]. In recent years, the monophasic variant of serovar Typhimurium $(S .1,4,[5], 12:-: 1,2)$ has started to be described in subclinically-infected pigs or pigs with diarrhea $[20,33]$. This serovar and its monophasic variant are highly pathogenic and often carry antimicrobial resistance genes, and are thus a relevant hazard to consumers [6].

The antimicrobial resistance profile of Salmonella has become an important topic in public health, since the selection of resistant strains on the farm can reach humans through the food chain and the environment [46]. While the tested strains were fully susceptible to all tested cephalosporins, indicating that extended beta lactamases producer strains were absent, a high percentage of MDR strains were identified, mainly presenting a resistance profile to ampicillin-tetracycline-sulfonamide. This profile is the most prevalent in studies reporting antimicrobial resistance in Salmonella isolated from swine [20,30]. Considering the hazard for humans though the resistance to the $3^{\text {rd }}$ and $4^{\text {th }}$ generations cephalosporins and fluoroquinolones are critically important, since they are the antibiotics that are used 
for the treatment of invasive salmonellosis or infections in children [46]. In this regard, the resistance to ciprofloxacin, which was found in $12.5 \%$ of the strains, is of concern.

In recent years, resistance to colistin, codified by genes $m c r$ carried in transferable plasmids, has been increasingly reported $[31,48]$. This is a matter of concern since colistin is considered the last resort drug, which is used for the treatment of human infections caused by bacteria resistant to all other antimicrobial classes. Most of the tested Salmonella strains (85\%) were inhibited by colistin concentrations $>2 \mu \mathrm{g} \cdot \mathrm{mL}^{-1}$ and thus, were considered non-susceptible according to the only available criteria [21]. Colistin resistance can be caused by chromosomal mutations or by the $m c r$ gene carried on plasmids. The latter can in turn be transferred horizontally amongst the bacterial population, allowing for the rapid shift for resistance [31,32]. The investigation of the $m c r-1$ gene among the Salmonella strains demonstrated that only $11.8 \%$ of the non-susceptible strains carried this gene. Although $m c r-1$ was the first colistin resistance gene to be identified, to date, five different $\mathrm{mcr}$ and their variants have been described [48]. Among them, mcr-1, $m c r-2$ and $m c r-3$ were described on plasmids carried by Enterobacteriaceae, and $m c r-1$ and $m c r-2$ proved to be highly prevalent in samples taken from swine in China $[31,48]$. Although in our study $m c r-1.1$ was the only variant identified in the strains subjected to WGS, other gene variants could be present in the other strains and could have been responsible for the observed MIC $\geq 4 \mu \mathrm{g} \cdot \mathrm{mL}-1$ profile.

All $m c r$-1-positive strains by PCR were identified as monophasic variants of $S$. Typhimurium isolated from intestinal contents; three presented a common resistance profile, were isolated from the same pig batch and their PFGE profiles were indistinguishable. These characteristics indicate that they might belong to a resistant clone carried in the gut of the pigs from this batch. This hypothesis was supported by WGS, which demonstrated a common profile of resistance genes in the strains.

All PFGE closely-related strains subjected to WGS shared several resistance genes: aadA2 (streptomycin resistance); aac(6')Iaa (amikacin and gentamicin resistance) and $b l a_{\text {TEM-1B }}$ (ampicillin resistance). All of these genes are widely distributed in Salmonella and other enterobacteria and are usually part of MDR profiles [22,29,30,37]. Additional genes commonly reported in Salmonella, such as tetB (tetracycline resistance), sul2 (sulfonamide resistance) and floR (amphenicol resistance), were also found in most of the strains. Regarding the fluoroquinolones, the five strains were phenotypically not resistant to ciprofloxacin, but carried mutations in gyrA, which confers resistance to nalidixic acid and reduces susceptibility to fluoroquinolones [2,38]. In two strains (\#74 and \#76), which were phenotypically intermediately resistant to ciprofloxacin, the plasmidial gene qnrB19 was also present. This gene also confers low resistance to fluoroquinolones and facilitates the development of mutations in gyrA [38]. All these findings indicate that these strains are already not fully susceptible to this antimicrobial class. This result together with the phenotypically-resistant strains detected in the disk diffusion test highlight the importance of the use restriction of this antimicrobial class to only therapeutic purposes in swine.

Besides the resistance profile identification, WGS allowed us to classify the monophasic variant $S$. Typhimurium strains into a sequence type (ST-19) frequently involved in foodborne outbreaks, including several in which pork was the likely source [23]. Moreover, ST-19 was likely to be the most frequent among Salmonella strains isolated from human infections in Brazil [35]. This constitutes an additional hazard for Salmonella control in pork, and demonstrates that resistant and pathogenic Salmonella strains may be continuously introduced in the slaughter process by pigs infected on the farm.

\section{CONCLUSIONS}

The profile of Salmonella carried in the intestinal contents of slaughter pigs is highly variable in terms of the frequency, number of bacteria, serovars, antimicrobial resistance and genotypes. Results indicate that the day-to-day variability in the prevalence and number of Salmonella in the intestinal contents of slaughter batches is likely to influence the frequency of contaminated pre-chill carcasses. Salmonella Typhimurium, isolated from the intestinal contents of slaughter pigs, may belong to genotypes involved in human disease and may carry several antimicrobial resistance genes. These aspects should be taken into account when planning the control of Salmonella in swine. 
MANUFACTURERS

${ }^{1}$ Nasco. Fort Atkinson, WI, USA.

${ }^{2}$ Oxoid Ltd. Hampshire, UK.

${ }^{3}$ Promega Biotecnogia do Brasil. São Paulo, SP, Brazil.

${ }^{4}$ Bio-Rad. Hercules, CA, USA.

${ }^{5}$ Loccus Biotecnologia. Cotia, SP, Brazil.

${ }^{6}$ Applied Maths. Kortrijk, Belgium.

${ }^{7}$ MicrobesNG. Birmingham, UK.

${ }^{8}$ Invitrogen Life Technologies. Carlsbad, CA, USA.

${ }^{9}$ Illumina Inc. San Diego, CA, USA.
Funding. This study was carried out with the support of the Coordination of Improvement of Higher Education Personnel - Brazil (CAPES) - Financing Code 001 (PNPD scholarship for E.F. Costa and C. Pissetti; PhD scholarship for G.O. Werlang; MSc scholarship for T. Vieira) and the National Council for Scientific and Technological Development (CNPq) (MSc scholarship for D. Paim).

Declaration of interest. The authors report no conflicts of interest. The authors alone are responsible for the content and writing of paper.

\section{REFERENCES}

1 Alban L., Baptista F.M., Mogelmose V., Sorensen L.L., Christensen H., Aabo S. \& Dahl J. 2012. Salmonella surveillance and control for finisher pigs and pork in Denmark- A case study. Food Research International. 45: 656-665.

2 Almeida F., Seribelli A.A., Medeiros M.I.C., Rodrigues D.P., Varani A.M., Luo Y., Allard M.W. \& Falcão J.P. 2018. Phylogenetic and antimicrobial resistance gene analysis of Salmonella Typhimurium strains isolated in Brazil by whole genome sequencing. PLOS One. 13(8): e0201882.

3 Bankevich A., Nurk S., Antipov D., Gurevich A.A., Dvorkin M., Kulikov A.S., Lesin V.M., Nikolenko S.I., Pham S., Prjibelski A.D., Pyshkin A.V., Sirotkin A.V., Vyahhi N., Tesler G., Alekseyev M.A. \& Pevzner P.A. 2012. SPAdes: a new genome assembly algorithm and its applications to single-cell sequencing. Journal of Computing Biology. 19(5): 455-477.

4 Baptista F.M., Dahl J. \& Nielsen L.R. 2010. Factors influencing Salmonella carcass prevalence in Danish pig abattoirs. Preventive Veterinary Medicine. 95(3-4): 231-238.

5 Bolger A.M., Lohse M. \& Usadel B. 2014. Trimmomatic: a flexible trimmer for Illumina sequence data. Bioinformatics. 30(15): 2114-2120.

6 Bone A., Noel H., Le Hello S., Pihier N., Danan C., Raguenaud M.E., Salah S., Bellali H., Vaillant V., Weill F.X. \& Jourdan-da Silva N. 2010. Nationwide outbreak of Salmonella enterica serotype 4,12:i:- infections in France, linked to dried pork sausage. Euro Surveillance. 15(24): pii $=19592$.

7 Borch E., Nesbakken T. \& Christensen H. 1996. Hazard identification in swine slaughter with respect to foodborne bacteria. International Journal of Food Microbiology. 30: 9-25.

8 Brasil. Ministério da Agricultura Pecuária e Abastecimento. 2018. Instrução Normativa $N^{\circ} 58$ de 17 de dezembro de 2018. Available at: <http://www.in.gov.br/materia/-/asset_publisher/Kujrw)TZC2Mb/content/id/55882955>.

9 Brasileiro A.C.M., Santos M.A.S., Sá C.V.G.C., Rodrigues C.S. \& Haddad J.P.A. 2017. National prevalence of Salmonella spp. in pork slaughterhouses under Federal Inspection in Brazil, 2014/2015. In: 12th International Symposium on the Epidemiology and Control of Biological, Chemical and Physical Hazards in Pigs and Pork (Foz do Iguaçu, Brazil). pp.55-58.

10 Buncic S. \& Sofos J. 2012. Interventions to control Salmonella contamination during poultry, cattle and pig slaughter. Food Research International. 45: 641-655.

11 Busschaert P., Geeraerd A.H. \& Van Impe J.F. 2010. Estimating distributions out of qualitative and (semi) quantitative microbiological contamination data for use in risk assessment. International Journal of Food Microbiology. 138: 260-269.

12 Carriço J.A., Pinto F.R., Simas C., Nunes S., Sousa N.G., Frazão N., de Lencastre H. \& Almeida J.S. 2005. Assessment of band-based similarity coefficients for automatic type and subtype classification of microbial isolates analyzed by pulsed-field gel electrophoresis. Journal of Clinical Microbiology. 43(11): 5483-5490.

13 Clinical and Laboratory Standards Institute (CLSI). 2018. Performance standards for antimicrobial disk and dilution susceptibility test for bacteria isolated from animals; Approved standard. CLSI supplement VET08. 4th edn. Wayne: Clinical and Laboratory Standards Institute, 99p.

14 Clinical and Laboratory Standards Institute (CLSI). 2018. Performance standards for antimicrobial susceptibility testing. CLSI document M100-S28. 28th edn. Wayne: Clinical and Laboratory Standards Institute, 282p. 
15 Corbellini L.G., Bianco Júnior A., Costa E.F., Duarte A.S.R., Albuquerque E.R., Kich J.D., Cardoso M. \& Nauta M. 2016. Effect of slaughterhouse and day of sample on the probability of a pig carcass being Salmonella-positive according to the Enterobacteriaceae count in the largest Brazilian pork production region. International Journal of Food Microbiology. 228: 58-66.

16 Davies P. 2017. Salmonella control in pigs in the USA - focus on slaughter hygiene. Available at: <https://www.pig333. com/articles/salmonella-control-in-pigs-in-the-usa-\%E2\%80\%93-focus-on-slaughter-hygiene_13103/>. [Accessed online in July 2018].

17 De Busser E.V., De Zutter L., Dewulf J., Houf K. \& Maes D. 2013. Salmonella control in live pigs and at slaughter. The Veterinary Journal. 196(1): 20-27.

18 Delignette-Muller M.L. \& Dutang C. 2015. fitdistrplus: an R Package for Fitting Distributions. Journal of Statistical Software. 64(4): 1-34.

19 Di Ciccio P., Ossiprandi M.C., Zanardi E., Ghidini S., Belluzzi G., Vergara A. \& Ianeri A. 2016. Microbiological contamination in three large-scale pig slaughterhouses in Northern Italy. Italian Journal of Food Safety. 5: 219-223.

20 European Food Safety Authority (EFSA) and European Centre for Disease Prevention and Control (ECDC). 2017. The European Union summary report on trends and sources of zoonoses, zoonotic agents and food-borne outbreaks in 2016. EFSA Journal. 15(12): 5077-5305.

21 European Committee on Antimicrobial Susceptibility Testing (EUCAST). 2018. Breakpoint tables for interpretation of MICs and zone diameters. Version 9.0,2018. Available at:<http://www.eucast.org/clinical_breakpoints/>. [Accessed online in December 2018].

22 Garneau-Tsodikova S. \& Labby K.J. 2016. Mechanisms of resistance to aminoglycoside antibiotics: overview and perspectives. MedChemComm. 7(1): 11-27.

23 Gymoese P., Sorensen G., Litrup E., Olsen J.E., Nielsen E.M. \& Torpdahl M. 2017. Investigations of outbreaks of Salmonella enterica serovar Typhimurium and its monophasic varians using whole-genome sequencing, Denmark. Emerging Infectious Diseases. 3(10): 1631-1639.

24 International Standard Organization (ISO). 2002. ISO6579:2002. Microbiology of food and animal feeding stuffs - Horizontal method for the detection of Salmonella spp. Geneva: ISO, 27p.

25 Kich J.D., Coldebella A., Mores N., Nogueira M.G., Cardoso M., Fratamico P.M., Call J.E., Fedorka-Cray P. \& Luchansky J.B. 2011. Prevalence, distribution, and molecular characterization of Salmonella recovered from swine finishing herds and a slaughter facility in Santa Catarina, Brazil. International Journal of Food Microbiology. 151: 307-313.

26 Kich J.D., Costa E.F., Triques N., Nogueira M.G, Dalla Costa O., Coldebella A., Kummer A. \& Cardoso M. 2016. Assessment of different cut-off values of the ELISA-Typhimurium for the discrimination of swine herds with Salmonella isolation. Semina: Ciências Agrárias. 37: 3107-3113.

27 Kich J.D., Schwarz P., Silva L.E., Coldebella A., Piffer I.A., Vizzoto R. \& Cardoso M. 2007. Development and application of an enzyme-linked immunosorbent assay to detect antibodies against prevalent Salmonella serovars in swine in southern Brazil. Journal of Veterinary Diagnostic Investigation. 19(5): 510-517.

28 Larsen M.V., Cosentino S., Rasmussen S., Friis C., Hasman H., Marvig R.L., Jelsbak L., Sicheritz-Pontén T., Ussery D.W., Aarestrup F.M. \& Lund O. 2012. Multilocus sequence typing of total genome sequenced bacteria. Journal of Clinical Microbiology. 50(4): 1355-1361.

29 Looft T., Johson T.A., Allen H.K., Bayles D.O., Alt D.P., Stedtfeld R.D., Sul W.J., Stedfeld T., Chai B., Cole J.R., Hashsham S.A., Tiedje J.M. \& Stanton T.B. 2012. In-feed antibiotic effects on the swine intestinal microbiome. Procedures of the National Academy of Science USA. 109: 1691-1696.

30 Lopes G.V., Pissetti C., Pellegrini D.C.P., Silva L.E. \& Cardoso M. 2015. Resistance phenotypes and genotypes of Salmonella enterica subsp. enterica isolates from feed, pigs, and carcasses in Brazil. Journal of Food Protection. 78(2): 407-413.

31 Liu J.Y., Liao T.L., Huang W.C., Liu Y.M., Wu K.M., Lauderdale T.L., Tsai S.F., Kuo S.C. \& Kuo H.C. 2018. Increased mcr-1 in pathogenic Escherichia coli from diseased swine, Taiwan. Journal of Microbiology, Immunology and Infection. https://doi.org/10.1016/j.jmii.2018.10.011

32 Liu Y.Y., Wang Y., Walsh T.R., Yi L.X., Zhang R., Spencer J., Doi Y., Tian G., Dong B., Huang X., Yu L.F, Gu D., Ren H., Chen X., L. L., He D., Zhou H., Liang Z., Liu J.H. \& Shen J. 2016. Emergence of plasmid-mediated colistin resistance mechanism $M C R-1$ in animals and human beings in China: a microbiological and molecular biological study. The Lancet. Infectious Diseases. 16(2): 161-168. 
33 Meneguzzi M., Kich J.D., Rebelatto R., Pissetti C., Kuchiishi S.S., Reis A.T., Guedes R.M.C., Leão J.A. \& Reichen C. 2017. Salmonella clinical isolates from Brazilian pig herds: genetic relationship and antibiotic resistance profiling. In: 12th International Symposium on the Epidemiology and Control of Biological, Chemical and Physical Hazards in Pigs and Pork (Foz do Iguaçu, Brazil). pp.170-174.

34 Paim D. 2016. Perfil de excreção de Salmonella em suínos ao abate e presença de carcaças positivas no pré-resfriamento. 52f. Porto Alegre, RS. Dissertação (Mestrado em Ciências Veterinárias) - Programa de Pós-graduação em Ciências Veterinárias, Universidade Federal do Rio Grande do Sul.

35 Panzenhagen P.H.N., Paul N.C., Conte Junior C.A., Costa R.G., Rodrigues D.P. \& Shah D.H. 2018. Genetically distinct lineages of Salmonella Typhimurium ST313 and ST19 are present in Brazil. International Journal of Medical Microbiology. 308: 306-316.

36 Pearce R.A., Bolton D.J., Sheridan J.J., McDowell D.A, Blair I.S. \& Harrington D. 2004. Studies to determine the critical control points in pork slaughter hazard analysis and critical control point systems. International Journal of Food Microbiology. 90: 331-339.

37 Pissetti C., Werlang G.O., Kich J.D. \& Cardoso M. 2017. Genotyping and antimicrobial resistance in Escherichia coli from pig carcasses. Pesquisa Veterinária Brasileira. 37(11): 1253-1260.

38 Pribul B.R., Festivo M.L., Souza M.M.S. \& Rodrigues D.P. 2016. Characterization of quinolone resistance in Salmonella spp. isolates from food products and human samples in Brazil. Brazilian Journal of Microbiology. 47: 196-201.

39 R Core Team. 2017. A language and environment for statistical computing. R Foundation for Statistical Computing, Vienna, Austria. Available at: <http//www.R-project.org>. [Accessed online in May 2018].

40 San Roman B., Garrido V., Sánchez S., Martínez-Ballesteros I., Garaizar J., Mainar-Jaime R.C., Migura-Garcia L. \& Grilló M.J. 2018. Relationship between Salmonella infection, shedding and serology in fattening pigs in lowmoderate prevalence areas. Zoonoses and Public Health. 65: 481-489.

41 Seemann T. 2014. Prokka: rapid prokaryotic genome annotation. Bioinformatics. 30(14): 2068-2069.

42 Silva L.E., Dias V., Ferronatto A., Guerra P., Berno L., Triches N., Kich J.D., Corbellini L.G. \& Cardoso M. 2012. Longitudinal dissemination of Salmonella enterica clonal groups through the slaughter process of Salmonella-positive pig batches. Journal of Food Protection. 75(9): 1580-1588.

43 Silva N., Junqueira V.C.A., Silveira N.F.A., Taniwaki M.H., Santos R.F.S. \& Gomes R.A.R. 2010. Manual de Métodos de Análises Microbiológicas de Alimentos e Água. 4.ed. São Paulo: Varela, 624p.

44 Tavares M.F.P. 2013. Avaliação da influência da etapa do abate Shechita na população de Salmonella sp. e de microorganismos indicadores em carcaças de frango. 60f. São Paulo, SP. Dissertação (Mestrado em Ciências dos Alimentos) - Programa de Pós-graduação em Ciências dos Alimentos, Universidade de São Paulo.

45 van Hoek H.A.M., Jonge R.A., van Overbeek M.W., Bouw E., Pielaat A., Smid J.H., Malorny B., Junker E., Löfström C., Pedersen K., Henk A.J.M. \& Heres L. 2012. A quantitative approach towards a better understanding of the dynamics of Salmonella spp. in a pork slaughter-line. International Journal of Food Microbiology. 153(1-2): 45-52.

46 World Health Organization (WHO) 2017. WHO list of Critically Important Antimicrobials for human medicine. Available at: <https://www. who.int/foodsafety/publications/cia2017.pdf?ua=1>. [Accessed online in June 2018].

47 Zankari E., Hasman H., Cosentino S., Vestergaard M., Rasmussen S., Lund O., Aarestrup F.M. \& Larsen M.V. 2012. Identification of acquired antimicrobial resistance genes. Journal of Antimicrobial Chemotherapy. 67(11): 2640-2644.

48 Zhang J., Chen L., Wang J., Yassin A.K., Butaye P., Kelly P., Gong J., Guo W., Li J., Li M., Yang F., Feng Z., Jiang P., Song C., Wang Y., You J., Yang Y., Price S., Qi1 K., Kang Y. \& Wang C. 2018. Molecular detection of colistin resistance genes ( $m c r-1, m c r-2$ and $m c r-3)$ in nasal/oropharyngeal and anal/cloacal swabs from pigs and poultry. Nature. 8: 3705-3714.

49 Zhang S., Yin Y., Jones M.B., Zhang Z., Deatherage Kaiser B.L., Dinsmore B.A., Fitzgerald C., Fields P.I. \& Deng X. 2015. Salmonella serotype determination utilizing high-throughput genome sequencing data. Journal of Clinical Microbiology. 53(5): 1685-1692.

50 Zweifel C., Baltzer D. \& Stephan R. 2005. Microbiological contamination of cattle and pig carcasses at five abattoirs determined by swab sampling in accordance with EU Decision 2001/471/EC. Meat Science. 69(3): 559-566.

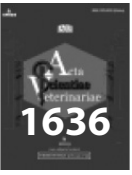

